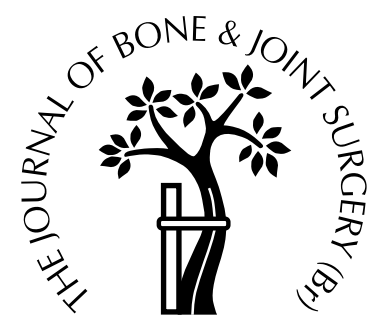

\title{
Arthrodesis of flail or partially flail wrists using a dynamic compression plate without bone grafting
}

\author{
G. A. Anderson, B. P. Thomas \\ From the Christian Medical College Hospital, Vellore, India
}

$\mathbf{B}_{\mathrm{a}}^{\mathrm{e}}$ etween June 1991 and May 1996 we carried out arthrodesis on 15 patients with flail or partially flail wrists using an AO/ASIF dynamic compression plate (DCP) without a bone graft. The wrist was approached through the second extensor compartment. The minimum follow-up was for 24 months with a mean of 34.2 months. All 15 wrists fused without major complications at a mean of 11.9 weeks. Stabilisation improved the function of the hand affected with paralysis and the appearance of the extensively paralysed upper limb with a flail hand. In the absence of bony abnormality fusion can be obtained with a DCP alone without the need for bone grafting.

J Bone Joint Surg [Br] 2000;82-B:566-70.

Received 24 August 1999; Accepted after revision 23 December 1999

Fusion of the wrist involves the radiocarpal, midcarpal and carpometacarpal joints in the radiocentral axis. The scaphotrapezial joint is excluded to avoid limitation of movement of the thumb. ${ }^{1}$ Earlier techniques used grafts of the iliac bone ${ }^{1,2}$ through a dorsal or a radial approach. ${ }^{3}$ The distal ulna served as the graft with the ulnar approach. ${ }^{4}$ These techniques required long periods of immobilisation ${ }^{1}$ and resulted in rates of pseudarthrosis as high as $20 \%$ to $28.5 \% .^{5}$ The use of internal fixation, initially with Steinmann pins or Rush nails, ${ }^{6}$ reduced the period of immobilisation and the incidence of pseudarthrosis to $8.3 \%$. $^{5}$ The introduction of the AO-dynamic compression plate (DCP) (Synthes; Mathys Medical Ltd, Bettlach, Switzerland) by the AO/ASIF group ${ }^{7,8}$ combined with bone grafting gave a very high rate of success and has become the most popular method. ${ }^{7-10}$ Distal fixation of the DCP to the third ${ }^{10}$ metacarpal is favoured over that to the second metacarpal. ${ }^{8,9}$

G. A. Anderson, MCh Orth, FACS, Professor of Orthopaedics, Head of Hand Research Unit

B. P. Thomas, MS Orth, Senior Lecturer

Christian Medical College Hospital, Vellore 632 004, Tamil Nadu, India.

Correspondence should be sent to Professor G. A. Anderson.

(C)2000 British Editorial Society of Bone and Joint Surgery 0301-620X/00/410505\$2.00
Rates of union of $100 \%$ have been reported ${ }^{8}$ with the DCPbone-grafting combination for rheumatoid arthritis, secondary osteoarthritis due to Keinböck's disease and post-traumatic complications in the wrist.

We have studied the outcome of arthrodesis using a DCP without bone grafting in wrists with no intrinsic radiocarpal and intracarpal abnormality in patients with paralysis of the extensors and flail wrists.

\section{Patients and Methods}

Between June 1991 and May 1996, we carried out an arthrodesis on 15 patients with paralysis affecting the wrist. Their mean age was 24.5 years (11 to 53). The duration and cause of paralysis, the side operated on, the time taken for fusion, and the period of follow-up are shown in Table I. MRC grading was used to assess motor power. There was associated paralysis of the shoulder, elbow and hand in 12 patients (Table II).

Preoperative assessment showed that all patients managed their basic activities of daily living with their normal hands. Of the 15 patients, 11 used their affected hands for dressing and toilet. Extensive weakness meant that it was impossible to assess accurately in 14 patients.

Operative technique. A curvilinear dorsal incision was made centred at Lister's tubercle. The wrist was approached through the second extensor compartment by incising it in the long axis. The third and fourth extensor compartments were elevated subperiosteally with the tendons and retracted towards the ulna without entering the compartments. This dissection required care, particularly when tendon transfers for extension of the fingers and thumb were planned for a later stage. The distal radio-ulnar joint was not disturbed. The articular cartilage of all adjacent joints was removed meticulously with a small burr or sharp osteotome and a fine rongeur. The denuded surfaces were brought together with the wrist in $15^{\circ}$ to $20^{\circ}$ of dorsiflexion (mean, 18.5). A $3.5 \mathrm{~mm}$ DCP of appropriate length was contoured and applied in compression mode to obliterate the intercarpal and radiocarpal gaps. Bone grafting was not done and small irregularities at the margins of the opposing articulations were left. A suction drain was inserted before the wound was closed. A volar plaster-of-Paris slab was applied until removal of the sutures and then a wrist cast

THE JOURNAL OF BONE AND JOINT SURGERY 
Table I. Details of the 15 patients who underwent wrist arthrodesis

\begin{tabular}{|c|c|c|c|c|c|c|c|c|}
\hline Case & $\begin{array}{l}\text { Age } \\
(\mathbf{y r})\end{array}$ & Gender & Side & $\begin{array}{l}\text { Types of } \\
\text { paralysis* }\end{array}$ & $\begin{array}{l}\text { Duration of } \\
\text { paralysis } \\
\text { (mth) }\end{array}$ & $\begin{array}{l}\text { Time for } \\
\text { fusion } \\
\text { (weeks) }\end{array}$ & $\begin{array}{l}\text { Follow-up } \\
\text { (mth) }\end{array}$ & Complications \\
\hline 1 & 38 & $\mathrm{M}$ & $\mathrm{R}$ & Birth palsy & 456 & 14 & 26 & None \\
\hline 2 & 14 & $\mathrm{~F}$ & $\mathrm{R}$ & Birth palsy & 168 & 11 & 38 & $\begin{array}{l}\text { Fracture of radius at proximal } \\
\text { screw hole at } 30 \text { months }\end{array}$ \\
\hline 3 & 11 & M & $\mathrm{L}$ & Pprp & 84 & 12 & 36 & None \\
\hline 4 & 17 & $\mathrm{~F}$ & $\mathrm{R}$ & Pprp & 156 & 11 & 36 & None \\
\hline 5 & 32 & M & $\mathrm{L}$ & Pprp & 348 & 12 & 32 & None \\
\hline 6 & 23 & M & $\mathrm{L}$ & Pprp & 204 & 13 & 40 & None \\
\hline 7 & 19 & M & $\mathrm{R}$ & Pprp & 204 & 11 & 28 & None \\
\hline 8 & 19 & M & $\mathrm{R}$ & Birth palsy & 228 & 12 & 30 & None \\
\hline 9 & 21 & M & $\mathrm{L}$ & Birth palsy & 252 & 13 & 39 & None \\
\hline 10 & 42 & M & $\mathrm{R}$ & Brach plex & 36 & 10 & 25 & None \\
\hline 11 & 23 & M & $\mathrm{L}$ & Brach plex & 40 & 12 & 36 & None \\
\hline 12 & 46 & M & $\mathrm{R}$ & Brach plex & 34 & 10 & 40 & None \\
\hline 13 & 29 & M & $\mathrm{L}$ & $\begin{array}{l}\text { Radial N \& partial } \\
\text { Median N injury }\end{array}$ & 24 & 12 & 28 & None \\
\hline 14 & 19 & $\mathrm{~F}$ & $\mathrm{R}$ & Cerebral palsy & 228 & 14 & 38 & $\begin{array}{l}\text { Loss of } 5^{\circ} \text { extension } \\
\text { at } 38 \text { months }\end{array}$ \\
\hline 15 & 14 & M & $\mathrm{R}$ & VIC & 20 & 11 & 41 & None \\
\hline
\end{tabular}

* Pprp, post-polio residual paralysis; Brach plex, brachial plexus injury; VIC, Volkmann's ischaemic contracture

for a further three weeks. A thermoplastic splint with velcro straps was provided for a further three weeks.

The minimum follow-up was for 24 months with a mean of 34.2 months. Three months after arthrodesis additional procedures were carried out on 12 patients to improve the function of the hand and to provide elbow flexion and shoulder stabilisation (Table II). Two patients did not have any reconstruction for disability of the proximal joints because of the absence of transferable tendons in one and the acceptance of the long-standing situation in the other.

\section{Results}

The patients were assessed clinically for pain, swelling and abnormal movement at the arthrodesed wrist after the sixth postoperative week. Anteroposterior (AP) and lateral radiographs were taken every two to three weeks, depending on the regularity and frequency of attendance. Fusion occurred at a mean of 11.9 weeks (10 to 14) in all 15 wrists (Figs 1 and 2). There was no evidence of pseudarthrosis. In a young patient with residual birth palsy, fracture of the radius occurred at the proximal screw site of the DCP 30 months after fusion of the wrist because of a fall. The implants were removed and an appropriately long new DCP was used to fix the fracture, excluding the fused wrist. The patient with cerebral palsy was found to have lost $5^{\circ}$ of wrist extension at a late follow-up of 38 months. There was no radiological evidence of loosening of the screws or the plate.

In 11 patients, there was improved function of the hand. Gross manual dexterity was evaluated using the block-into- box method. In these 11 hands, including those which had additional transfers to restore finger and thumb extension, the mean improvement of cylindrical grasp using the Jamar dynamometer (Fig. 3) was $21.4 \%$ (19 to 25 ) when compared with their normal hands. The other four could be used only as a stabiliser or for bimanual activities, such as carrying light articles. In the youngest patient, aged 11 years, there were no problems related to shortening of the forearm or ulnar overgrowth after fusion of the wrist. The DCP was removed a year later. Four other patients had their implants removed at a mean of 20 months after wrist fusion, in three at the request of the patient.

\section{Discussion}

In patients with paralysed upper limbs who are late in seeking treatment, assessment is needed of contractures of the joints, the muscle power suitable for transfer, the time interval that the stages of reconstruction require, and the nature and extent to which established procedures can be suitably chosen for the patient's needs. Priority is given to the evaluation of sensory function and the careful assessment of available tendons which can be transferred whenever possible. Patients usually expect dynamic functional restoration. Stabilising procedures such as arthrodesis as an alternative for a weak joint, require careful consideration. In the developing world, injuries to the brachial plexus in adults as a result of road-traffic accidents are on the increase and are approaching the more common causes such as poliomyelitis and birth palsy.

There are few reports on fusion for wrists affected with 


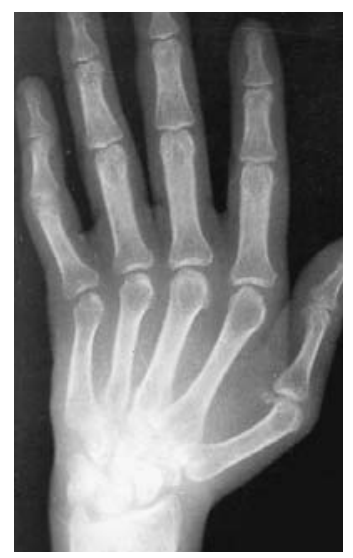

Fig. 1a

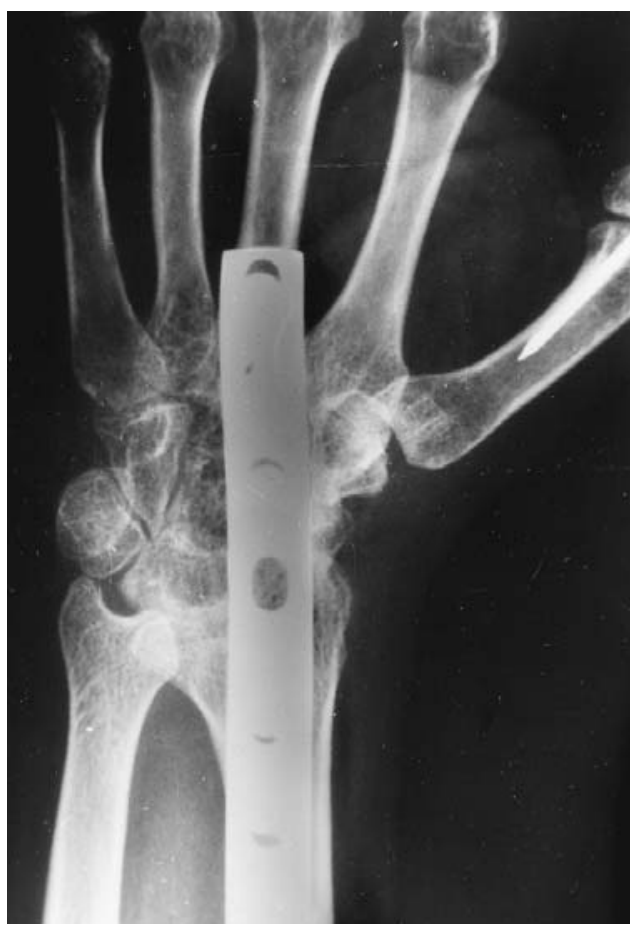

Fig. 1c

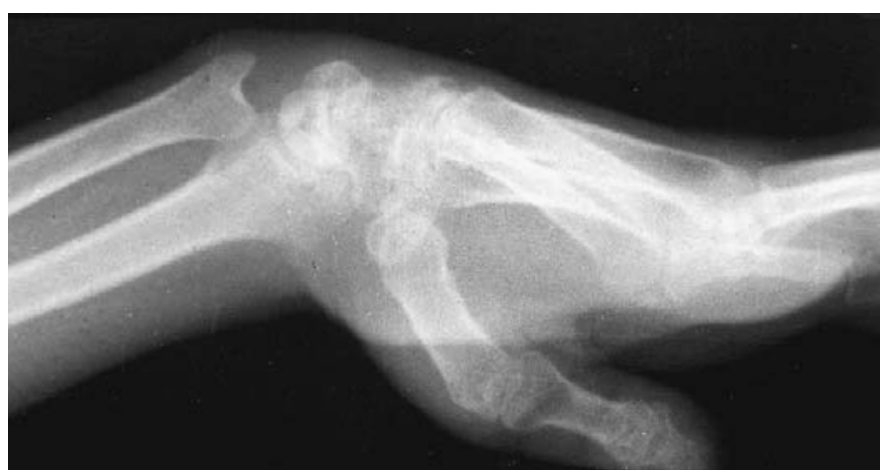

Fig. $1 b$

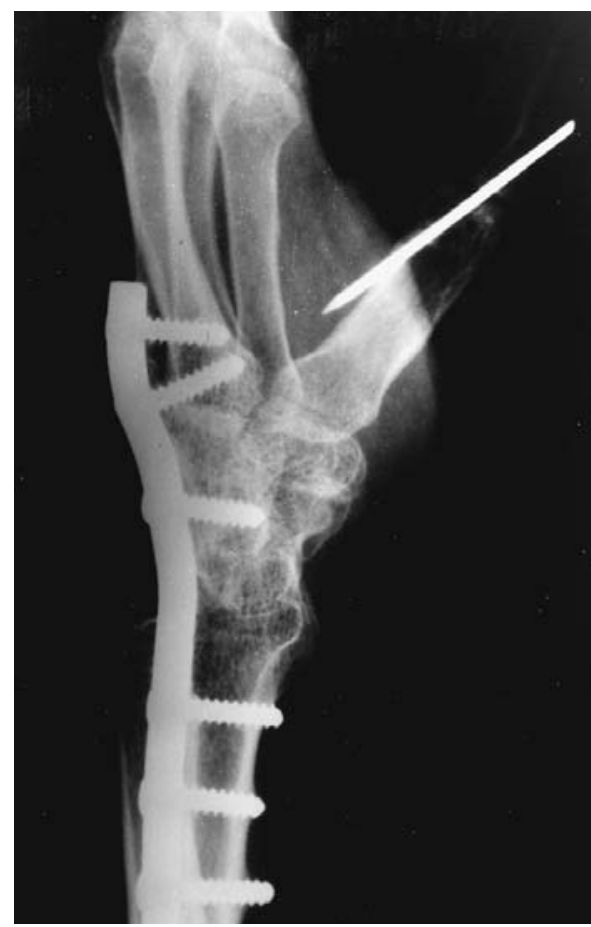

Fig. 1d

Case 1. Figures 1a and $1 \mathrm{~b}$ - AP (a) and lateral (b) radiographs of a wrist with long-standing paralysis of adjacent muscles showing normal carpal joints without arthritic changes. Figures $1 \mathrm{c}$ and $1 \mathrm{~d}-\mathrm{AP}(\mathrm{c})$ and lateral (d) radiographs after arthrodesis with a contoured DCP and no bone graft. There is excellent fusion as seen by trabeculae crossing the radius and carpus. The metacarpal joint of the thumb was transfixed with a Kirschner wire before fusion.

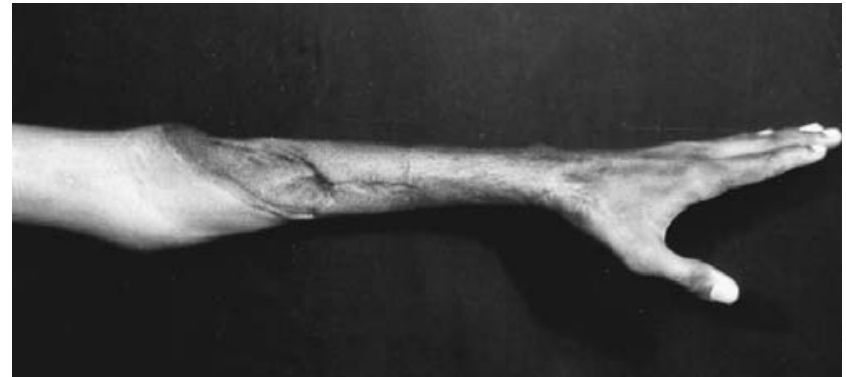

Fig. 2a

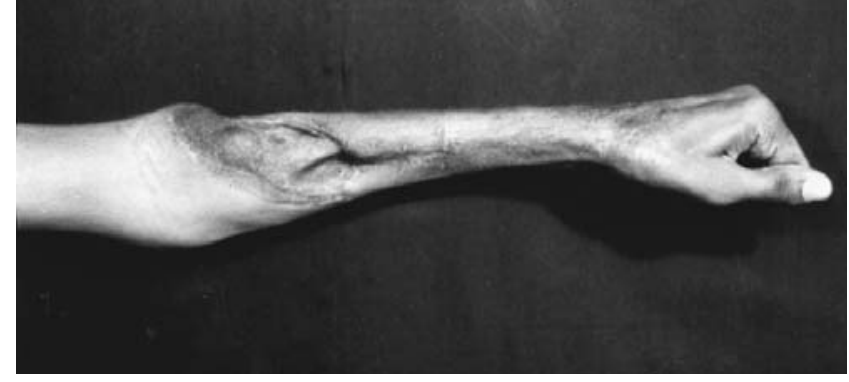

Fig. 2b

Case 13. Photographs showing (a) a stable wrist with excellent finger and thumb extension and (b) finger flexion after wrist fusion with a DCP without bone grafting and transfer of flexor carpi ulnaris to extensor digitorum communis and extensor pollicus longus at a second procedure. 
Table II. Patterns of associated paralysis of the ipsilateral limb and additional procedures performed

\begin{tabular}{|c|c|c|c|c|c|}
\hline \multirow[b]{2}{*}{ Case } & \multicolumn{4}{|c|}{ Patterns of paralysis* } & \multirow[b]{2}{*}{ Additional procedures* } \\
\hline & Shoulder & Elbow & Wrist & Hand & \\
\hline 1 & $\begin{array}{l}\text { Abd gr } 3 \\
\text { Add gr } 4 \\
\text { Int rotn } \\
\text { contr }\end{array}$ & $\begin{array}{l}\text { Fl gr } 3 \\
\text { Ext gr } 2\end{array}$ & $\begin{array}{l}\text { Fl gr } 4 \\
\text { Ext gr } 0\end{array}$ & $\begin{array}{l}\text { Fl gr } 3 \\
\text { Ext Gr } 0 \\
\text { Intrin gr } 4\end{array}$ & $\begin{array}{l}\text { Ext reconstrn } \\
\text { Flrst MP fusion }\end{array}$ \\
\hline 2 & $\begin{array}{l}\text { Abd gr } 3 \\
\text { Add gr } 3 \\
\text { Int rotn contr } \\
\text { with posterior } \\
\text { subluxation }\end{array}$ & $\begin{array}{l}\text { Fl gr } 3 \\
\text { Ext gr } 2\end{array}$ & Flail & Flail & Scott's glenoplasty \\
\hline 3 & $\begin{array}{l}\text { Abd gr } 0 \\
\text { Add gr } 3 \\
\text { Int and ext rotn } \\
\text { gr } 0\end{array}$ & $\begin{array}{l}\text { Fl gr } 3 \\
\text { Ext gr } 3\end{array}$ & $\begin{array}{l}\text { Fl gr } 4 \\
\text { Ext gr } 0\end{array}$ & $\begin{array}{l}\text { Fl gr } 3 \\
\text { Ext gr } 1 \\
\text { Intrin gr } 3\end{array}$ & $\begin{array}{l}\text { Shoulder fusion } \\
\text { Ext reconstrn }\end{array}$ \\
\hline 4 & Flail & $\begin{array}{l}\text { Fl gr } 4 \\
\text { Ext gr } 2\end{array}$ & $\begin{array}{l}\text { Fl gr } 4 \\
\text { Ext gr } 0\end{array}$ & $\begin{array}{l}\text { Fl gr } 3 \\
\text { Ext gr } 0 \\
\text { Intrin gr } 2\end{array}$ & $\begin{array}{l}\text { Shoulder fusion } \\
\text { First CMC joint fusion, } \\
\text { Ext reconstrn }\end{array}$ \\
\hline 5 & $\begin{array}{l}\text { Abd gr } 3 \\
\text { Add gr } 4 \\
\text { Ext rotn gr } 3\end{array}$ & $\begin{array}{l}\text { Fl gr } 1 \\
\text { Ext gr } 4\end{array}$ & $\begin{array}{l}\text { Fl gr } 5 \\
\text { Ext gr } 1\end{array}$ & $\begin{array}{l}\text { Fl gr } 4 \\
\text { Ext gr } 1 \\
\text { Intrin gr } 3\end{array}$ & Steindler flexoroplasty \\
\hline 6 & $\begin{array}{l}\text { Abd gr } 4 \\
\text { Add gr } 4 \\
\text { Ext rotn gr } 3\end{array}$ & $\begin{array}{l}\text { Fl gr } 0 \\
\text { Ext gr } 3\end{array}$ & $\begin{array}{l}\text { Fl gr } 4 \\
\text { Ext gr } 0\end{array}$ & $\begin{array}{l}\text { Fl gr } 4 \\
\text { Ext gr } 3 \\
\text { Intrin gr } 2\end{array}$ & Steindler flexoroplasty \\
\hline 7 & Flail & $\begin{array}{l}\text { Fl gr } 3 \\
\text { Ext gr } 2\end{array}$ & $\begin{array}{l}\text { Fl gr } 4 \\
\text { Ext gr } 0\end{array}$ & $\begin{array}{l}\text { Fl gr } 3 \\
\text { Ext gr } 1 \\
\text { Intrin gr } 2\end{array}$ & $\begin{array}{l}\text { First CMC joint fusion } \\
\text { ext reconstrn }\end{array}$ \\
\hline 8 & $\begin{array}{l}\text { Abd gr } 3 \\
\text { Add gr } 4 \\
\text { Ext rotn gr } 3\end{array}$ & $\begin{array}{l}\text { Fl gr } 3 \\
\text { Ext gr } 2\end{array}$ & $\begin{array}{l}\text { Fl gr } 4 \\
\text { Ext gr } 0\end{array}$ & $\begin{array}{l}\text { Fl gr } 3 \\
\text { Ext gr } 0 \\
\text { Intrin gr } 3\end{array}$ & Ext reconstrn \\
\hline 9 & $\begin{array}{l}\text { Abd gr } 4 \\
\text { Add gr } 4 \\
\text { Ext rotn gr } 3\end{array}$ & $\begin{array}{l}\text { Fl gr } 3 \\
\text { Ext gr } 2\end{array}$ & Flail & Flail & Nil \\
\hline 10 & $\begin{array}{l}\text { Abd gr } 3 \\
\text { Add gr } 4 \\
\text { Int rotn contr }\end{array}$ & $\begin{array}{l}\mathrm{Fl}, \text { gr } 3 \\
\text { Ext gr } 2\end{array}$ & Flail & Flail & Nil \\
\hline 11 & $\begin{array}{l}\text { Abd gr } 4 \\
\text { Add gr } 4 \\
\text { Ext rotn }\end{array}$ & $\begin{array}{l}\text { Fl gr } 2 \\
\text { Ext gr } 0\end{array}$ & $\begin{array}{l}\text { Fl gr } 3 \\
\text { Ext gr } 1\end{array}$ & $\begin{array}{l}\text { Fl gr } 4 \\
\text { Ext gr } 0 \\
\text { Intrin gr } 4\end{array}$ & Nil \\
\hline 12 & $\begin{array}{l}\text { Abd gr } 4 \\
\text { Add gr } 4 \\
\text { Ext rotn gr } 3\end{array}$ & $\begin{array}{l}\text { Fl gr } 1 \\
\text { Ext gr } 3\end{array}$ & $\begin{array}{l}\text { Fl gr } 3 \\
\text { Ext gr } 1\end{array}$ & $\begin{array}{l}\text { Fl gr } 3 \\
\text { Ext gr } 0 \\
\text { Intrin gr } 2\end{array}$ & $\begin{array}{l}\text { Latissimus dorsi } \\
\text { transfer for elbow } \\
\text { flexion }\end{array}$ \\
\hline 13 & Normal & Normal & $\begin{array}{l}\text { Fl gr } 5 \\
\text { (only FCU) } \\
\text { Ext gr } 0\end{array}$ & $\begin{array}{l}\text { Fl gr } 5 \\
\text { (only FDP) } \\
\text { Ext gr 0 } \\
\text { UI Intrin gr } 5 \\
\text { Med intrin gr } 0 \\
\text { Thumb: } \\
\text { Flex and ext } 0\end{array}$ & Ext reconstrn \\
\hline 14 & Normal & $\begin{array}{l}\text { Flexors } \\
\text { spastic } \\
\text { Ext gr } 4\end{array}$ & $\begin{array}{l}\text { Fl gr } 3 \\
\text { (spasm }+ \text { ) } \\
\text { Ext gr } 0\end{array}$ & $\begin{array}{l}\text { Fl gr } 3 \\
(\text { Spasm }+) \\
\text { Ex gr } 2 \\
\text { Intrin gr } 3 \\
(\text { spasm }+)\end{array}$ & Flexor pronator slide \\
\hline 15 & Normal & Normal & $\begin{array}{l}\text { Fl gr } 2 \\
\text { Ext gr } 2\end{array}$ & $\begin{array}{l}\text { Fl gr } 3 \\
\text { Ext gr } 0 \\
\text { Intrin gr } 0\end{array}$ & $\begin{array}{l}\text { First CMC joint fusion } \\
\text { Flexor pronator slide }\end{array}$ \\
\hline
\end{tabular}

paralysis. $^{11-14}$ McKenzie ${ }^{12}$ and Makin ${ }^{13}$ described the use of a bone graft only in their series. Epstein ${ }^{11}$ did not use bone grafting or internal fixation for fusing a flail wrist. In the series of Brunelli et al, ${ }^{14}$ fixation of the graft by Kirschner wires along with immobilisation in plaster for three months to obtain fusion is described. With the introduction of the $\mathrm{DCP},{ }^{7,8}$ the beneficial features of rigidity with compression were added. Together with the DCP, bone grafting was recommended for obtaining fusion. ${ }^{9,10}$ Bone grafting with application of a DCP was required for carpal disorders such as avascular necrosis, collapse of the carpal rows due to arthritis or for salvaging failed intercarpal fusions. Bone grafting is considered as an option with rigid DCP fixation in flail and partially flail wrists since, in the 


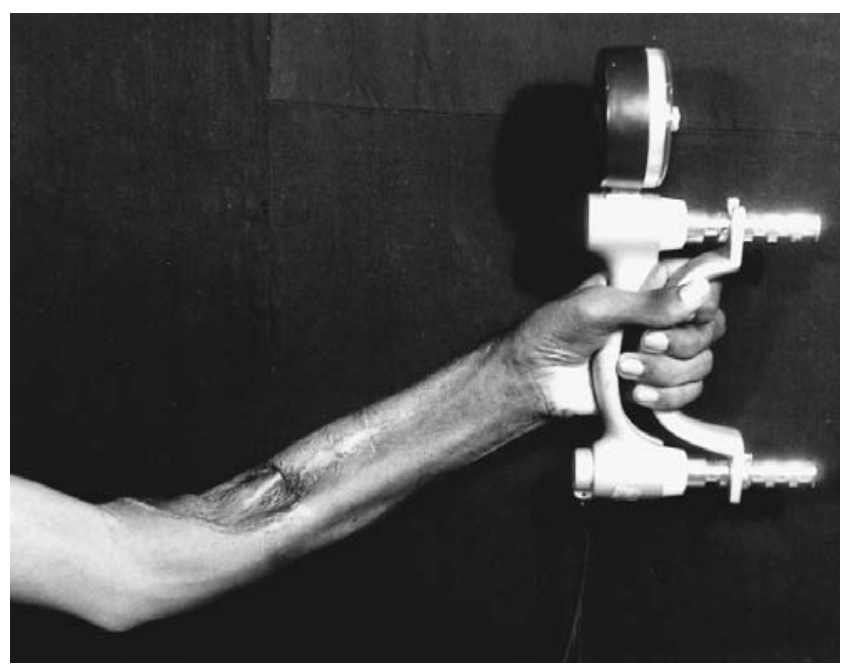

Fig. 3

Case 13. Cylindrical grasp assessment using the Jamar dynamometer.

absence of intrinsic abnormality of the carpus or secondary arthritic changes, the potential for fusion of these carpal bones is unaltered. Meticulous removal of articular cartilage from the adjacent radius, scaphoid and lunate, capitate and the base of the third metacarpal leaves even gaps with minimally disturbed contours between the opposing surfaces. These can be obliterated when the DCP is fixed in compression mode.

Our indications for arthrodesis in wrists with paralysed muscles have been similar to those already described $^{11,13,15-17}$ except for one patient with a total paralysis of the radial nerve and partial paralysis of the median nerve. The latter excluded the possibility of transfer of the tendon of pronator teres or of superficialis for wrist extension. Therefore, fusion of the wrist was followed by transfer of the flexor carpi ulnaris to obtain extension of the fingers and thumb (Fig. 2).

The wrist is fused in $15^{\circ}$ to $20^{\circ}$ of dorsiflexion ${ }^{15}$ for the patient's satisfaction and for cosmetic reasons. In our series, the mean angle of fusion was $18.5^{\circ}$ of dorsiflexion. Liebolt ${ }^{17}$ has mentioned neutral deviation to improve cosmesis and to prevent a weak grip. This is essential for hyperlax digits and supple hands commonly noted in Asians and for patients with post-polio paralysis ${ }^{18}$ or birth palsy. In these individuals wrists fused in radial or ulnar deviation tend to result in the development of angular deformities in the small distal joints which contribute to a weak grip. These secondary problems may be exaggerated when tendon transfers are done later.

Early mobilisation of the digits and reduction of postoperative stiffness have been noticeable after wrist arthrodesis using a DCP. The fingers and thumb begin to function better with whatever power their flexors and extensors possess. This is probably due to the flexor and extensor muscles of the digits not dissipating force at the stabilised wrist. Fusion of the wrist has been reported to improve the appearance of the hand in paralysed limbs ${ }^{12,19}$ and, when the hand has been totally flail, it provides a prop for a bimanual grip.

Arthrodesis of flail and partially flail wrists using a DCP and without bone graft leads to predictable union. Stability of the wrist in mild dorsiflexion and neutral deviation allows the weak digits to function better. In more severely paralysed hands there is a better appearance and it contributes to stable bimanual activity. Our approach to the wrist articulations only through the second compartment to place the DCP without entering the third and fourth extensor compartments, allows subsequent reconstruction by tendon transfer for thumb and finger extension to function smoothly.

The authors wish to thank Dr R. Thomas and Mr M. Prabhakaran of the Hand and Leprosy Reconstructive Surgery Department, for retrieving patients records and documenting the follow-up assessments.

No benefits in any form have been received or will be received from a commercial party related directly or indirectly to the subject of this article.

\section{References}

1. Butler AA. Arthrodesis of the wrist joint. Am Journ Surg 1949: 625-30.

2. Campbell CJ, Keokarn T. Total and subtotal arthrodesis of the wrist: inlay technique. J Bone Joint Surg [Am] 1964;46-A:1520-33.

3. Haddad RJ, Riordan DC. Arthrodesis of the wrist: a surgical technique. J Bone Joint Surg [Am] 1967;49-A:950-4.

4. Smith-Petersen MN. A new approach to the wrist joint. J Bone Joint Surg 1940;22:122-4.

5. Clendenin MB, Green DP. Arthrodesis of the wrist: complications and their management. J Hand Surg 1981;6:253-7.

6. Millender LH, Nalebuff EA. Arthrodesis of the rheumatoid wrist: an evaluation of sixty patients and a description of a different surgical technique. J Bone Joint Surg [Am] 1973;55-A:1026-34.

7. Müller ME, Allgöwer M, Schneider R, Willenegger H. Manual of internal fixation: techniques recommended by the AO group. Second ed. Berlin, etc: Springer-Verlag, 1979.

8. Heim V, Pfeiffer KM. Small fragment set manual. 1st and 2nd eds. Berlin, etc: Springer-Verlag, 1974 and 1982.

9. Larsson SE. Compression arthrodesis of the wrist: a consecutive series of 23 cases. Clin Orthop 1974;99:146-53.

10. O'Bierne J, Boyer MI, Axelrod TS. Wrist arthrodesis using a dynamic compression plate. JBone Joint Surg [Br] 1995;77-B: 700-4.

11. Epstein S. Arthrodesis for flail wrist. Am J Surg 1930;8:621-2.

12. MacKenzie IG. Arthrodesis of the wrist in reconstructive surgery. J Bone Joint Surg [Br] 1960;42-B:60-4.

13. Makin M. Wrist arthrodesis in paralyzed arms of children. J Bone Joint Surg [Am] 1977;59:312-6.

14. Brunelli G, Vigasio A, Battiston B, Brunelli F, Guizzi P. Arthrodesis of the wrist in cases of hand paralysis: personal technique. Ann Chir Main Memb Supr 1990;9:47-53.

15. Stein I. Gill turnabout radial graft for wrist fusion. Surg Gynaecol Obstet 1958;106:231-2.

16. Steindler A. Orthopedic operations on the hand. JAMA 1918;18: 1288-9.

17. Liebolt FL. Surgical fusion of the wrist joint. Surg Gynecol Obstet 1938;66:1008-23.

18. Anderson GA, Lee V, Sundararaj GD. Oppenensplasty by extensor indicis and flexior digitorum superficialis tendon transfer. J Hand Surg [Br] 1992;17-B:611-4.

19. d'Aubigné M. Symposium on reconstructive surgery of the paralysed upper limb. Section of Orthopaedics, Sir H J Seddon, President. Proc $R$ Soc Med 1949; XLII:831-843. 